\title{
Enhanced weekend service: an affordable means to increased hospital procedure volume
}

\section{Chaim M. Bell, Donald A. Redelmeier}

$\mathrm{D}$ ecreasing waiting times for medical procedures and diagnostic tests has become a major focus for health policy in Canada. Although some commentators have called for increased infrastructure to handle the demand, building and equipping new hospitals comes with enormous costs and delays, which raises the question of whether our current levels of efficiency can be improved. Because many hospitals do not operate at full capacity every day, we wondered how many more procedures could be completed if services were increased on weekends.

We examined 6 procedures that reflect diverse technologies and are regularly used in acute medical care: esophageal gastroduodenoscopy, echocardiography, coronary angiography, pulmonary ventilation-perfusion scanning, MRI and fibreoptic bronchoscopy. ${ }^{1}$ These procedures require specialized equipment and, in our clinical experience, entail substantial delays for inpatients. To obtain realistic projections of the demand for each procedure based on past practice patterns, we identified consecutive patients admitted to all Ontario acute-care hospitals through an emergency department from Apr. 1, 1988, to Mar. 31, 1997 , to determine how many underwent 1 of the 6 procedures as their most significant procedure when in hospital. ${ }^{2}$

The administrative database analysis revealed a total of 3789917 emergency hospital admissions to all acute-care hospitals during the 10-year interval; among these, 126759 patients had 1 of the 6 selected procedures (Table 1). We found that 120855 (95\%) procedures were performed on a weekday and $5904(5 \%)$ on a weekend. For every procedure, the observed weekday to weekend proportion differed substantially from the theoretical $71 \%$ to $29 \%$ split.

Given the large decrease in the volume of procedures performed on weekends compared with weekdays, we examined 3 scenarios to explore the effect of using weekend days to increase productivity. These scenarios were as follows: (1) all 7 days running at the same capacity as the best weekday; (2) weekend days unchanged and all 5 weekdays running at the same capacity as the average weekday capacity; (3) weekend days running at $50 \%$ of the average weekday capacity (Table 2). As expected, the first scenario generated a large increase in the potential volume of procedures. We also observed that, even if weekend days operated at only $50 \%$ of best weekday capacity, a large increase in the absolute number of procedures could be realized (most notably for echocardiography, with 700 additional procedures).

Focusing on echocardiography alone at the 110 hospi- tals in the cohort, we identified the 2 hospitals that demonstrated the most and the least skewed distribution of weekday to weekend services ( $99 \%$ of procedures performed on weekdays vs. $1 \%$ on weekends, and $85 \%$ on weekdays v. $15 \%$ on weekends, respectively). The hospital with the most skewed distribution, which performed a total of 7950 echocardiograms, would increase the total by 508 procedures per year under the first scenario. The hospital with the least skewed distribution performed a total of 2037 echocardiograms over the 10-year period and would increase the total by 150 procedures per year under the first scenario. In both hospitals, all scenarios led to potential increases in output ranging from $3 \%$ to $74 \%$.

\section{Interpretation}

Anecdotal evidence suggests that increasing weekend hospital capacity is feasible, safe and practical. ${ }^{3,4}$ Our work demonstrates that even conservative growth in weekend service can achieve an increase in procedure volume of about $15 \%$. More significant effects can be attained in specific and targeted situations, depending on the individual hospital's circumstances. To our knowledge, such models of increasing weekend activity to increase the productivity of a health care system have not been examined previously.

Most earlier studies of waiting times and queues have focused on outpatient delays for high-technology procedures. Other initiatives have targeted rate-limiting departments to realize savings in fixed "hoteling" costs (which may outweigh any marginal direct procedural costs). ${ }^{3}$ Reports have also described some success with initiatives for weekend cardiology procedures, augmented surgery and physiotherapy programs, and after-hours radiologic and nuclear medicine investigations. ${ }^{3-6}$ These initiatives aim to reduce hos-

Table 1: Day of performance for 6 procedures regularly used in acute medical care

\begin{tabular}{lrrr}
\hline Procedure & $\begin{array}{c}\text { Total } \\
n=126759\end{array}$ & $\begin{array}{c}\text { Weekday, } \\
\text { no. }\end{array}$ & $\begin{array}{c}\text { Weekend, no. } \\
\text { (\% of total)* }\end{array}$ \\
\hline Esophageal & 45167 & 41565 & $3602(8.0)$ \\
gastroduodenoscopy & 40965 & 39972 & $993(2.4)$ \\
Echocardiogram & 21690 & 21356 & $334(1.5)$ \\
Coronary angiogram & 10639 & 10207 & $432(4.1)$ \\
Ventilation perfusion scan & 4325 & 4027 & $298(6.9)$ \\
MRI of any structure & 3973 & 3728 & $245(6.2)$ \\
\hline Fibreoptic bronchoscopy & & &
\end{tabular}


Table 2: Projected yearly increases in procedure volume resulting from enhanced weekend service

\begin{tabular}{lccc}
\hline & \multicolumn{3}{c}{ Scenario; no. of additional procedures performed (\% increase) } \\
\cline { 2 - 4 } Procedure & $\begin{array}{c}\text { All } 7 \text { days at } \\
\text { same capacity as } \\
\text { best weekday }\end{array}$ & $\begin{array}{c}\text { Weekend days } \\
\text { unchanged; weekdays } \\
\text { at best capacity }\end{array}$ & $\begin{array}{c}\text { Weekend days at 50\% of } \\
\text { average weekday capacity; } \\
\text { weekdays unchanged }\end{array}$ \\
\hline Esophageal gastroduodenoscopy & $2016(45)$ & $510(11)$ & $471(10)$ \\
Echocardiogram & $2172(53)$ & $480(12)$ & $700(17)$ \\
Coronary angiogram & $1200(55)$ & $271(13)$ & $394(18)$ \\
Ventilation perfusion scan & $877(83)$ & $366(34)$ & $161(15)$ \\
MRI of any structure & $193(45)$ & $44(10)$ & $50(12)$ \\
Fibreoptic bronchoscopy & $177(45)$ & $37(9)$ & $1827(14)$ \\
All & $6635(52)$ & $1708(14)$ & \\
\hline
\end{tabular}

pital length of stay but still preserve (or enhance) the delivery of services. Further, they sometimes provide faster results and have the potential to alter clinical decisions. ${ }^{5}$

Human resource issues in health care are substantial, yet creative scheduling in echocardiography (and other services) employing free-market mechanisms may be a means of increasing weekend staffing. ${ }^{3}$ Other obstacles to consider include service time for equipment, the quality of life of clinicians, the handling of on-call responsibilities and the goals of unions. Weekends are also typified by a lack of availability of administrators, supervisors and support staff. Moreover, our analysis focused on admitted patients only; hence, additional weekend capacity could also be considered to shorten outpatient queues and satisfy the preferences of some patients and their families.

Given that the administrative data we used may contain coding errors, our projections are preliminary. However, the proportions of procedures performed on weekends were similar to those described elsewhere. ${ }^{7}$ Also, the basic assumptions of extrapolation we used in our simulations might not fully reflect real-world potential, local cultures and complex system factors (e.g., elective queues). For example, our analysis did not account for holidays, which may dilute the observed weekday/weekend comparisons and alter some of the estimates of productivity. Our analysis does not account for nursing salaries and premiums for other salary costs beyond conventional full-time staffing. However, even with increased wages for weekend work, some health care institutions have found it economical to increase the amount of care provided on weekends. ${ }^{3,4}$ Further, we included only those patients who were admitted to hospital through emergency departments; patients admitted electively and those requiring the same procedures as outpatients only add to the skewed delivery of care, as they rarely obtain procedures on weekends. Finally, we did not incorporate into our analysis complex salary structures reflecting particular marketplace conditions.

Waiting for information and procedures can jeopardize sound decision-making, delay important clinical care and affect patient outcomes., ${ }^{2,5}$ Thus wasted time is an important component of the differences between weekday and week- day processes of care, and interventions to reduce wasted time issue might have implications for quality of care. In the quest for more timely medical care, staffing efficiencies may provide a more feasible solution for some hospitals than capital expansion. Constructing new staffing schedules is likely to cost less and to create fewer delays and disruptions than constructing new buildings.

This article has been peer reviewed.

From the Departments of Medicine and of Health Policy, Management and Evaluation, University of Toronto, and the Institute for Clinical Evaluative Sciences (Bell, Redelmeier); Department of Medicine, St. Michael's Hospital (Bell); and the Department of Medicine, Patient Safety Service, and Clinical Epidemiology Unit of Sunnybrook and Women's College Health Sciences Centre, Toronto, Ont. (Redelmeier)

Competing interests: None declared.

Contributors: Both authors contributed substantially to the conception and design of the project. Chaim Bell conducted the analysis and both authors interpreted the data. Both authors participated in writing the manuscript and approved the submitted version.

Acknowledgements: Chaim Bell is funded by Clinician Scientist Awards from the Canadian Institutes of Health Research and the University of Toronto Department of Medicine. Donald Redelmeier was funded by a Canada Research Chair in Medical Decision Sciences. We thank Alex Kopp for help with computer programming. We are also grateful to Ross Baker, Allan Detsky, Ed Etchells, Claudio Martin, Art Slutsky and Jack Tu for comments on drafts of this manuscript.

\section{References}

1. Fuchs VR, Sox HCJ. Physicians' views of the relative importance of thirty medical innovations. Health Aff (Millwood) 2001;20(5):30-42.

2. Bell CM, Redelmeier DA. Waiting for urgent procedures on the weekend among emergently hospitalized patients. Am 7 Med 2004;117:175-81.

3. Moore JDJ. Hospital saves by working weekends. Mod Healthc 1996;26:82,84,99.

4. Krasuski RA, Hartley LH, Lee TH, Polanczyk CA, Fleischmann KE. Weekend and holiday exercise testing in patients with chest pain [see comments] 7 Gen Intern Med 1999;14:10-4.

5. Eustance C, Carter N, O'Doherty M, Coakley AJ. Effect on patient management of a weekend "on-call" nuclear medicine service. Nucl Med Commun 1994;15:388-91.

6. Holden MK, Daniele CA. Comparison of seven- and five-day physical therapy coverage in patients with acute orthopedic disorders. Phys Ther 1987; 67:1240-6.

7. Hahn PF, Gervais DA, O’Neill MJ, Mueller PR. Nonvascular interventional procedures: analysis of a 10-year database containing more than 21000 cases. Radiology 2001;220:730-6.

Correspondence to: Dr. Chaim M. Bell, St. Michael's Hospital, 30 Bond St., Toronto ON M5B 1W8; fax 416 864-5485;

bellc@smh.toronto.on.ca 